RENATA HARUMI CRUZ

\title{
INTERAÇÃO ENTRE ANTICORPOS ESPECÍFICOS E CÉLULAS DENDRÍTICAS DE PACIENTES ALÉRGICOS
}

Dissertação apresentada ao Programa de PósGraduação em Imunologia do Instituto de Ciências Biomédicas da Universidade de São Paulo, para obtenção do título de Mestre em Ciências.

São Paulo

2018 
RENATA HARUMI CRUZ

\section{INTERAÇÃO ENTRE ANTICORPOS ESPECÍFICOS E CÉLULAS DENDRÍTICAS DE PACIENTES ALÉRGICOS}

Dissertação apresentada ao Programa de PósGraduação em Imunologia do Instituto de Ciências Biomédicas da Universidade de São Paulo, para obtenção do título de Mestre em Ciências.

Área de concentração: Imunologia Orientador: Prof. Dr. Antonio Condino Neto

Versão corrigida. A versão original eletrônica, encontra-se disponível na Secretaria de Pósgraduação que aloja o Programa

São Paulo

2018 


\section{R E S U M O}

CRUZ, Renata Harumi. Interação entre anticorpos específicos e células dendríticas de pacientes alérgicos. 2018. 90 f. Dissertação (Mestrado em Imunologia). - Instituto de Ciências Biomédicas, Universidade de São Paulo, São Paulo, 2018.

A atopia caracteriza-se pela tendência de um indivíduo a produzir IgE em quantidade elevada, em resposta a um alérgeno específico, levando ao desenvolvimento de asma, rinite ou eczema. Todavia, a manifestação do fenótipo da alergia depende da interação de fatores genéticos e exposição a alérgenos ambientais. Desta forma, o alérgeno é processado e apresentado aos linfócitos T, que desenvolvem uma resposta imune Th2, exacerbada característica da atopia. A principal célula que está envolvida na comunicação entre a imunidade inata e adaptativa é a célula dendrítica (DC) cuja função é capturar, processar e apresentar o antígeno aos linfócitos. As DCs imaturas capturam o antígeno e migram do tecido para o órgão linfóide periférico, onde elas se diferenciam em DCs maduras e apresentam o antígeno aos linfócitos T naive. Assim, os linfócitos $\mathrm{T}$ naive podem se diferenciar em subtipos de linfócitos efetores como: linfócitos Th1 e Th2. Esses linfócitos auxiliam na produção de anticorpos pelos linfócitos B na resposta imune humoral contra patógenos específicos. O sistema imune humoral compreende cinco classes de imunoglobulinas: IgG, IgM, IgD, IgE e IgA e sua produção sofre influência da imunidade celular. Desta forma, alérgenos provenientes de ácaros como, Dermatophagoides pteronyssinus, podem levar à inflamação alérgica, alterando a produção de anticorpos. Tendo em vista evidências que demonstram a interação das DCs com anticorpos, propomos investigar sua influência na apresentação dos principais alérgenos da poeira domiciliar e sua modulação sobre a resposta imune em indivíduos alérgicos e não alérgicos.

Palavras-chave: Alergia, Alérgeno, Células dendríticas, Linfócitos TCD4+, Imunoglobulinas. 


\section{A B S T R A C T}

CRUZ, R. H. Interaction among specific antibodies and dendritic cells from allergic patients. 2018. 90 s. Dissertation (Master degree in Immunology). Institute of Biomedical Sciences, University of São Paulo, São Paulo, 2018.

Atopy is characterized by the trend of an individual to produce high amounts of $\mathrm{IgE}$ in response to a specific allergen, leading to the development of asthma, rhinitis or eczema. However, the manifestation of the allergy phenotype depends on the interaction of genetic factors and exposure to environmental allergens. In this way, the allergen is processed and presented to the $\mathrm{T}$ lymphocytes, which develop a Th2 immune response, exacerbated characteristic of atopy. The main cell that is involved in the communication between innate and adaptive immunity is the dendritic cell (DC) whose function is to capture, process and present the antigen to lymphocytes. Immature DCs capture the antigen and migrate from the tissue to the peripheral lymphoid organ, where they differentiate into mature DCs and present the antigen to naive T lymphocytes. Thus, naive T lymphocytes can differentiate into subtypes of effector lymphocytes such as Th1 and Th2 lymphocytes. These lymphocytes assist in the production of antibodies by B lymphocytes in the humoral immune response against specific pathogens. The humoral immune system comprises five classes of immunoglobulins: $\operatorname{IgG}$, IgM, IgD, IgE and $\operatorname{IgA}$ and their production is influenced by cellular immunity. In this way, allergens from mites such as Dermatophagoides pteronyssinus, can lead to allergic inflammation, altering the production of antibodies. In view of evidence demonstrating the interaction of DCs with antibodies, we propose to investigate their influence on the presentation of the main house dust allergens and their modulation on the immune response in allergic and non-allergic individuals.

Keywords: Allergy, Allergen, Dendritic cells, CD4 + $\mathrm{T}$ lymphocytes, Immunoglobulins. 
"Você escreve para mudar o mundo... Se você alterar, mesmo que seja por um milimetro, a maneira como as pessoas olham para a realidade, então você pode mudá-lo." 


\subsection{Alergia}

\subsubsection{Características Gerais}

O termo alergia foi apresentado em 1906 por Clemens Von Pirquet, para descrever uma mudança na reação do sistema imune que ocorre devido a uma exposição inicial ao antígeno (sensibilização). A palavra alergia foi derivada do grego allos (outro) e ergon (trabalho) (THOMAS ET AL, 2010). O intuito de usar o significado da palavra alergia, por Clemens Von Pirquet, poderia ser tanto uma reação protetora, que conduzisse para imunidade, ou ser 'prejudicial', levando ao dano tecidual e reações adversas (THOMAS ET AL, 2010, HUBER, 2006).

A reação de hipersensibilidade do sistema imune é caracterizada pelo aumento exacerbado do nível de anticorpos do tipo IgE na circulação sanguínea, após o contato com baixas concentrações de alérgeno (LONDON, THARAKAN, RAMANATHAN, 2016). Este por sua vez, leva à ativação da reação inflamatória alérgica como: asma, rinoconjuntivite e eczema (YAZDANBAKHSH, KREMSNER, REE VAN, 2002).

Esta definição descreve a reação imune, entretanto, não inclui os sintomas clínicos. A atopia é um fator importante para o desenvolvimento das doenças alérgicas, embora o paciente atópico possa apresentar um teste positivo em resposta ao alérgeno sem desenvolvimento dos sintomas (BALDAÇARA ET $\mathrm{AL}, 2013)$.

As doenças alérgicas representam um problema de saúde que atinge grande parte da população. De acordo com os estudos epidemiológicos há um aumento na prevalência da asma, rinite alérgica, conjuntivite e dermatite atópica. Aproximadamente 1 bilhão de indivíduos no mundo são afetados pelas doenças supracitadas (TAN ET AL, 2016). Em casos mais extremos, as manifestações clínicas podem evoluir para anafilaxia e morte (HAWRYLOWICZ ET AL, 2005; RUTKOWSKI ET AL, 2014). A prevalência varia, geralmente sendo mais alta em 
países desenvolvidos em relação aos países em desenvolvimento (HAWRYLOWICZ ET AL, 2005).

A Organização Mundial de Alergia (WAO) estima que atualmente 235 milhões de pessoas em todo o mundo sofram de asma, a doença mais comum na infância (WORLD ALLERGY ORGANIZATION, 2014). No Brasil, a asma é responsável por 350.000 internações hospitalares por ano, 2.000 óbitos, e incontáveis consultas ambulatoriais e emergências, levando à ausência prolongada em atividades escolares e no trabalho (GALVÃO, CASTRO, 2005). No Brasil é também considerada a $4^{\text {a }}$ causa de hospitalizações pelo Sistema Único de Saúde (SUS), sendo a 3a entre jovens adultos (GALVÃO, CASTRO, 2005).

O aumento nos casos de alergia coincide com o período de grande modernização e urbanização, com o desenvolvimento econômico do país e com a melhoria das condições sanitárias. Como consequência, houve uma mudança no estilo de vida da população, levando as pessoas (principalmente crianças) a terem menos exposição a agentes microbianos, corroborando a 'hipótese da higiene' (SHARQUIE ET AL, 2013).

Tal hipótese foi inicialmente apresentada por Strachan em 1989 para explicar o porquê da ocorrência do aumento da asma e doenças alérgicas em países industrializados, associando a redução da carga microbiana na infância com o desenvolvimento de doenças alérgicas (NGOC ET AL, 2005). A teoria da higiene afirma que a falta de exposição a componentes microbianos na fase inicial da vida altera a pré-ativação do sistema imune, levando consequentemente ao aumento da suscetibilidade de doenças atópicas (STIEMSMA E TURVEY, 2017).

O mecanismo de manifestação das doenças alérgicas é complexo e influenciado por vários motivos, tais como: rota de exposição e dose do alérgeno, tempo de exposição, suscetibilidade genética e características do alérgeno (TAN ET AL, 2016). Sendo assim, a manifestação do fenótipo da alergia na maioria das vezes depende da interação de fatores genéticos e o envolvimento com o ambiente, ou seja, a exposição aos alérgenos ambientais: poeira domiciliar, pólen, ácaros, pêlos de animais, fezes de barata, etc (GREGORY, LLOYD, 2011; ROMAGNANI, 
2004). Essa combinação gera uma elevada prevalência e muitas das doenças alérgicas tornam-se crônicas (NUNES, 2003).

Componentes orgânicos de diversas origens, tais como: pólens, fibras vegetais, derivados dos artrópodes (ácaros e baratas) e animais (gatos e cachorros) são agentes potenciais responsáveis pelo desencadeamento das doenças alérgicas (HOLT, THOMAS, 2005). Esses componentes são conhecidos como alérgenos, os quais induzem a reação de hipersensibilidade do tipo I, provocando uma resposta celular Th2 do qual culmina na produção de IgE (GHOULEH ET AL, 2012).

\section{Dermatophagoides pteronissynus}

Desde o século XVII, já havia conhecimento de que a inalação de fragmentos de ácaros poderia causar asma e rinite, porém nada muito aprofundado sobre suas consequências (RAULF ET AL, 2015).

Somente em 1964, o grupo de Reindert Voorhort, e o casal Frits T. M. Spieksma e Marise Spieksma-Boezeman, provaram que não somente a presença de ácaros da poeira domiciliar coletados de amostras provenientes das casas são as principais fontes de alérgenos, mas também são encontradas em ambientes internos úmidos e secos (RAULF ET AL, 2015).

A identificação do gênero Dermatophagoides, mais conhecido como ácaros da poeira domiciliar (figura 1), foi resultado de muito trabalho e estudo de médicos e biólogos durante o período da pré-Segunda Guerra Mundial (SPIEKSMA, DIEGES, 2004). 
Figura 1 - Ácaro da poeira domiciliar

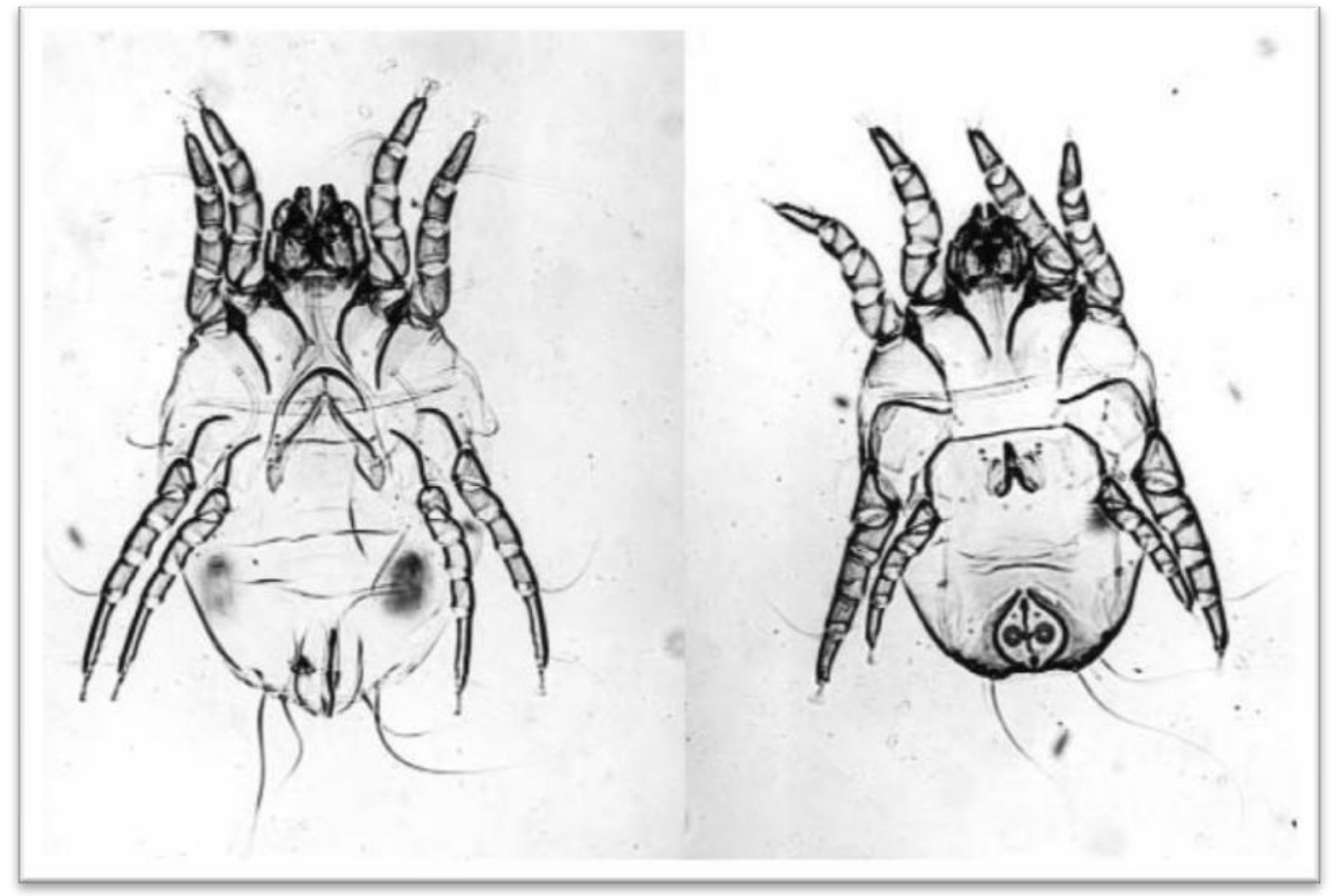

Dermatophagoides pteronyssinus, à esquerda, fêmea; e à direita, macho. Tamanho do corpo $~ 320 \mu \mathrm{m}$ (Adaptado de: SPIEKSMA, DIEGES, 2004).

Os ácaros são microrganismos chamados de poiquilotérmicos, pois não conseguem regular a sua própria temperatura corporal. Sua proliferação ótima é entre $75 \%$ a $80 \%$ da umidade relativa e numa temperatura de $25^{\circ} \mathrm{C}$ a $30^{\circ} \mathrm{C}$. São capazes de sobreviver em regiões onde há uma grande variação de temperatura e umidade, assim, utilizam seus mecanismos de escape como 'cavar' em áreas em que a umidade pode ser bem mantida, como sofás e colchões. Portanto, demoram meses para morrer, mesmo com pouca umidade e, assim, possuem o tempo suficiente para amplificar a dispersar suas substâncias alergênicas (BIAGTAN ET AL, 2014).

$\mathrm{Na}$ poeira domiciliar estão presentes componentes derivados do ácaro, tais como: grânulos de suas fezes, mas há também epitélios de animais, restos alimentares, esporos de fungos e fragmentos de insetos. Sendo que os alérgenos de ácaros são as principais moléculas na reação da hipersensibilidade. $\mathrm{O}$ ácaro da poeira domiciliar é representado principalmente pelo gênero Dermatophagoides $s p$., e pode ser encontrado em diversos locais, preferencialmente em regiões de 
clima tropical como Brasil, Estados Unidos (Flórida), Porto Rico e Venezuela (CRIADO , WANDALSEN, 2001).

Na cidade de São Paulo, por exemplo, observou-se que as espécies Dermatophagoides pteronissynus (Dp) e Blomia tropicalis (Bt) representam 50\% e $26 \%$ dos alérgenos presentes na poeira dos interiores domiciliares, respectivamente (SERRAVALLE, MEDEIROS, 1999). Um estudo realizado na cidade de Salvador demonstrou que os ácaros dessas espécies também são os principais indutores da sensibilização alérgica e responsáveis pelas maiores porcentagens de frequência de testes cutâneos positivos (SERRAVALLE, MEDEIROS, 1999).

O ácaro Dp pode induzir diretamente a resposta inflamatória, assim como a resposta imune mediada por IgE. Alguns estudos demonstraram que as enzimas provenientes de Dp são capazes de ativar os eosinófilos e células epiteliais dos brônquios, e induzir a liberação de mediadores inflamatórios provenientes dos mastócitos (LEE ET AL, 2008).

Alérgenos presentes na poeira domiciliar são capazes de ativar o sistema imune inato e iniciar uma resposta inflamatória, demonstrado pela atividade de protease dos alérgenos do grupo 1 de Dp e Dermatophagoides farinae (Der p 1 e Der f 1) - enzimas proteolíticas que induzem resposta pró-infamatória pelo rompimento do epitélio pulmonar). Já os alérgenos do grupo 2, Der p 2 e Der f 2 interagem com o sistema imune inato ativando as células dendríticas (DCs, dendritic cells) via receptor semelhante a Toll do tipo 2 e 4 (TLR, Toll likereceptor) e são também altamente alergênicos (Figura 2) (LISA, LLOYD, 2011; CALDERON ET AL, 2015). 
Figura 2 - Ativação do sistema imune inato pelos ácaros da poeira domiciliar.

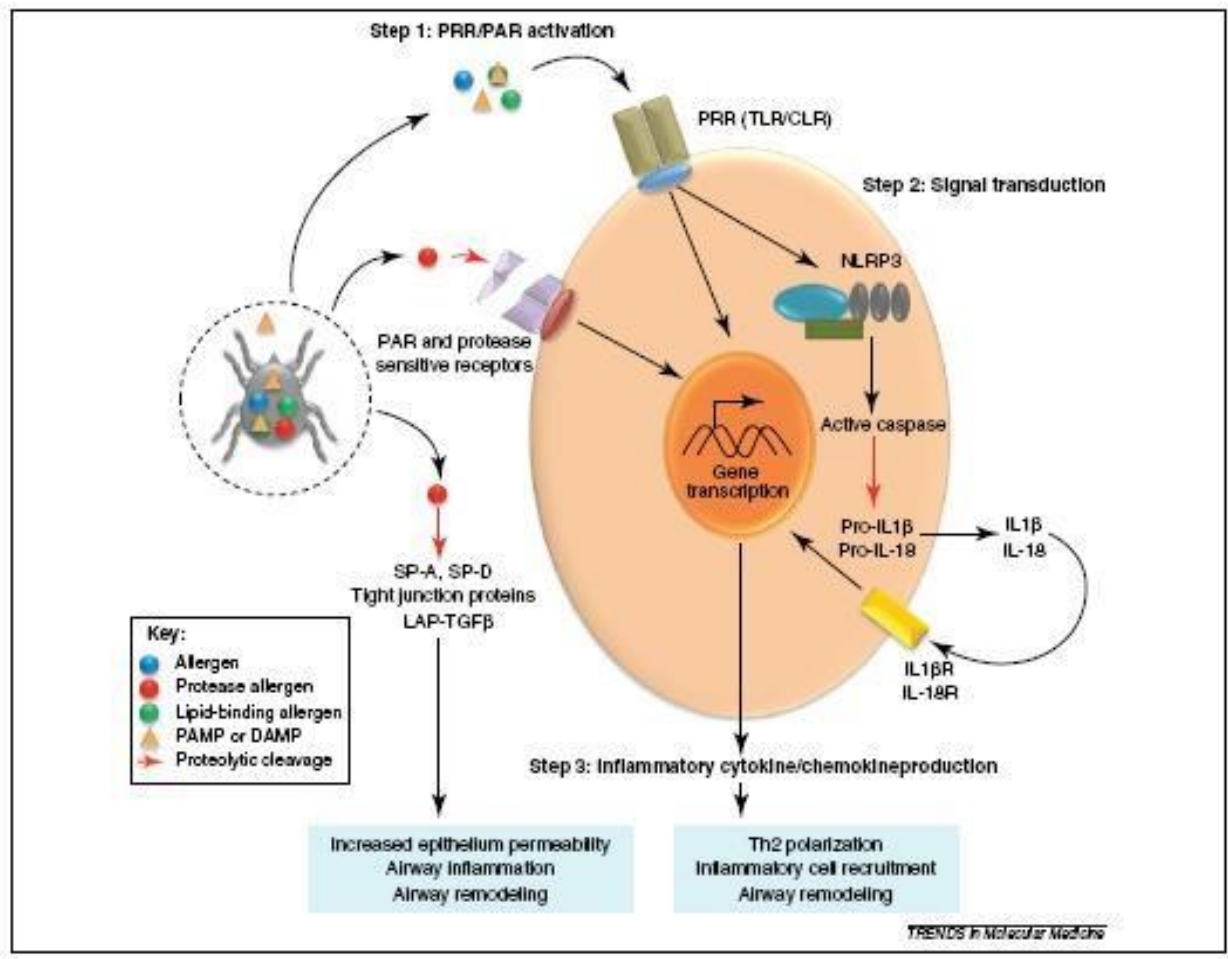

O sistema imune inato pode reconhecer os alérgenos por várias vias de sinalização. Dentre os quais, pela via de ativação dos receptores de reconhecimento padrão (PRRs), em que mecanismos intracelulares conduzem para transcrições de genes, encaminham para a síntese e liberação de citocinas inflamatórias. E o outro mecanismo é através da enzima proteolítica, dos quais, receptores da membrana, são clivados pela ação das proteases que também ativam a transcrição de genes para produção de citocinas inflamatórias (Adaptado de: JACQUET, 2011).

As doenças alérgicas têm uma resposta inflamatória que é desencadeada pelas citocinas produzidas pelos linfócitos Th2, mastócitos, basófilos e eosinófilos, os quais são: IL-4, IL-5, IL-10, IL-13, IL-17 e TGF-B (Nissen et al, 2013). Estas citocinas são produzidas e secretadas pelas células após estimulação por um alérgeno, como por exemplo, o alérgeno do Dp (BACHARIER, 2011).

Em estudos realizados com Der p 1, um dos principais alérgenos da poeira domiciliar, as DCs dos indivíduos sensíveis ao ácaro produziram mais IL-6 e IL10, porém menos IL-12 do que as DCs provenientes dos pacientes saudáveis (UPHAN, 2003). Além disso, os linfócitos T dos pacientes sensíveis ao alérgeno do 
ácaro Dp cultivados com DCs e Der p 1 produziram preferencialmente IL-4 do que IFN- $\gamma$ (HAMMAD ET AL, 2003).

\section{Resposta Imune e Alergia}

As reações de hipersensibilidade decorrem de uma reação exacerbada do sistema imune, frente a baixas concentrações de um antígeno, devido a prédisposição genética. A hipersensibilidade do tipo $I$ ocorre na presença da imunoglobulina da classe $\mathrm{E}$ (IgE); do tipo II é mediada pelos anticorpos IgG e IgM; o tipo III, é mediada pela formação de imunocomplexos; e o tipo $I V$, chamada de hipersensibilidade tardia, é uma reação mediada principalmente pelos linfócitos T CD4+ e macrófagos. No entanto, a resposta alérgica é classicamente definida como a reação de hipersensibilidade do tipo I (GERSHWIN, 2014; GRUMACH, 2001).

A inflamação alérgica ocorre em duas fases: a fase da sensibilização (indução) e a fase efetora. A fase de sensibilização envolve as células apresentadoras de antígenos (APCs, antigen presenting cells), linfócitos T, citocinas secretadas pelos linfócitos Th2, bem como: IL-4, IL-5 e IL-13, troca de classe dos linfócitos B e a secreção e ligação das IgE no receptor de FceRI de alta afinidade na membrana dos mastócitos e basófilos, tornando estas sensibilizadas (HE ET AL, 2013).

A fase efetora ocorre quando o indivíduo passa por subsequentes exposições aos mesmos alérgenos, ativando mecanismos celulares que realizam ligação cruzada com duas IgE adjacentes em mastócitos ou basófilos sensibilizados. Ocorre o recrutamento de células inflamatórias, a ativação e liberação de mediadores inflamatórios, como, histamina, cistenil-leucotrienos (CysLTs) e citocinas que promovem permeabilidade vascular, contração muscular e produção de muco (HE ET AL, 2013; RIZZO, 2008) (Figura 3). 
Figura 3 - Mecanismo clássico da inflamação alérgica

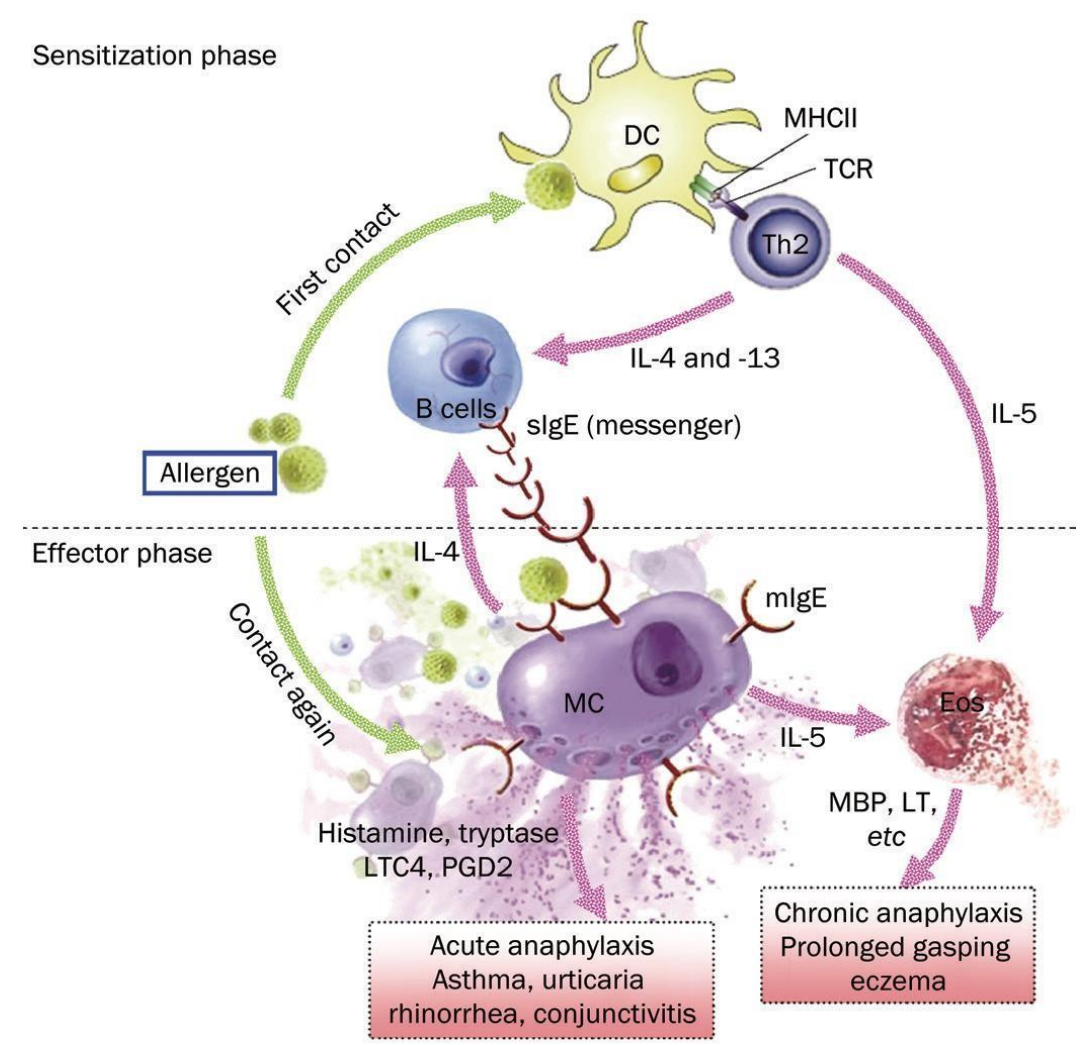

O processo fisiopatológico da inflamação alérgica envolve duas fases: a fase de indução: é o momento onde as DCs recebem o primeiro contato com o alérgeno, consequentemente tornam-se ativas e interagem com linfócitos Th para a mudança do perfil celular, para linfócitos Th2; através da liberação de citocinas específicas induz a mudança de classe dos linfócitos B para a produção de $\operatorname{IgE}$ que por sua vez, se liga aos receptores FceRI de alta afinidade tornando as células (mastócitos, basófilos) sensibilizadas. A fase efetora ocorre após o segundo contato com o mesmo alérgeno, fazendo com que as células sensibilizadas degranulem e liberem mediadores inflamatórios desencadeando manifestações clínicas (Adaptado de: He et al, 2013).

Além dos mastócitos, basófilos e eosinófilos, existem outras células do sistema imune que atuam durante a fase da manifestação alérgica, como por exemplo, as DCs e os linfócitos T.

\section{Células do Sistema Imune e Alergia}

Células dendríticas são derivadas da medula óssea. Morfologicamente, são bem características, apresentando finas projeções nas membranas semelhantes a uma estrela (BANCHEREAU, STEINMAN, 1998). As DCs são células conhecidas APCs, cujo nome que a caracteriza está associado à sua 
principal função. Elas desempenham o papel central no início da resposta primária e no aprimoramento da resposta imune secundária (GAETAN ET AL, 2002; GHAEMMAGHAMI ET AL, 2002).

Há diversos tipos de DCs identificadas tanto em humanos quanto em camundongos, dentre eles, há as DCs de origem mielóide, que são as células em estudo nesse trabalho. Estas células são encontradas no sangue periférico, representam entre $0.5 \%$ a $1.0 \%$ dos monócitos circulantes e possuem uma relação comum com monócitos e macrófagos. Para que possam sobreviver, necessitam do fator estimulador de colônia para granulócito e macrófago (GM-CSF, granulocytemacrophage colony stimulating factor), e também são compostos por marcadores de superfície como: CD11c, CD33 e CD13 e expressam receptores semelhantes a toll 2, 3, 4 e 8 (FRISCHMEYER-GUERRERIO, 2014; UPHAM, STUMBLES, 2003).

Em relação à característica da funcionalidade das DCs há duas formas conhecidas como: DC imatura e DC ativada. Elas possuem diferentes funções fundamentais para a imunidade. DCs imaturas são importantes pela sua alta capacidade de capturar e processar o antígeno embora possua baixa capacidade de estimular linfócitos T. Já as DCs ativadas, possuem alta capacidade de estimular os linfócitos $\mathrm{T}$ naive, os quais são fundamentais para iniciar as respostas imunes adquiridas aos antígenos proteicos (Figura 4), contudo, possuem baixa habilidade para capturar antígenos. (CELIA ET AL, 1997). 
Figura 4 - O papel das moDCs na resposta imune alérgica a ácaros de poeira domiciliar.

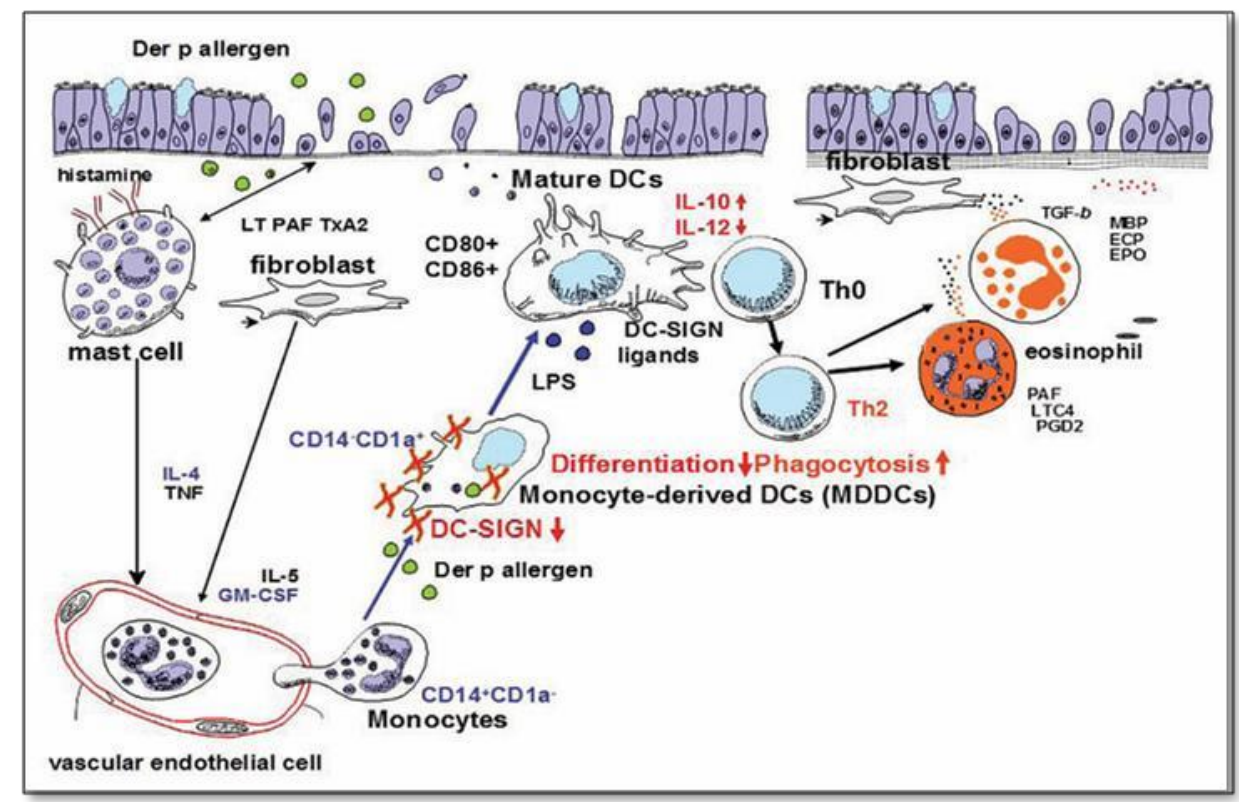

O alérgeno de Der $\mathrm{p}$ pode modular as células dendríticas derivadas dos monócitos (moDCs), conduzindo para diferenciação a s maturação num processo inflamatório alérgico (Adaptado de: WANG, 2013).

$\mathrm{Na}$ alergia, as DCs possuem um papel crucial no processo inicial e no controle da inflamação alérgica. As DCs e as células de Langerhans são particularmente importantes em doenças como a asma e o eczema, respectivamente (KAY, 2001). Sua função consiste no reconhecimento primário da estrutura nativa do alérgeno, processamento em peptídeo, e apresentação ao linfócito T CD4+ via molécula de MHC classe II das DCs, com subsequente polarização para a subpopulação de células T helper 2 (Th2) (SHAKIB ET AL, 2008).

$\mathrm{O}$ desenvolvimento diferencial dos linfócitos $\mathrm{T}$ naive em células funcionalmente efetoras, como linfócitos T helper 1 (Th1) ou linfócitos Th2, depende dos fatores presentes no microambiente no momento da ativação dos linfócitos T (HILKENS ET AL, 1997).

A diferenciação desses linfócitos necessita de basicamente três sinais estimulatórios, o qual é um processo importante para que haja uma resposta eficiente aos diferentes patógenos. $\mathrm{O}$ sinal 1 indica a propriedade molecular do antígeno para o receptor do linfócito T (TCR, T cell receptor). A expressão de 
moléculas co-estimuladoras na superfície das DCs, juntamente com proteínas produzidas durante a resposta imune inata, representa o sinal 2, ao qual a molécula co-estimuladora se liga a receptores de linfócitos $\mathrm{T}$ e o ativam (DELFI ET AL, 2014). A combinação do sinal 1 e o sinal 2 representa a ativação antígeno específica da célula $\mathrm{T}$ naive, promovendo o seu desenvolvimento em linfócitos $\mathrm{T}$ efetores e de memória. As citocinas provenientes das APCs representam o sinal 3, o qual conduz para a determinação dos subtipos de linfócitos $\mathrm{T}$ helper, por exemplo, altas concentrações de IL-12 polarizam para o tipo Th1 e este linfócito, por sua vez, produz IFN- $\gamma$ (KALINSKI ET AL., 1999).

Por outro lado, altas concentrações de IL-4 provenientes dos linfócitos T naives e baixas concentrações de IL-12, em resposta ao estímulo realizado pela apresentação de peptídeos pelas APCs, conduzem para o perfil do tipo Th2, onde esta célula irá produzir citocinas como: IL-4, IL-5, IL-13, IL-25, IL-31, IL-33 (Jutel, Akdis, 2011). A combinação do IL-1B, IL-6 com IL-23 independente do fator de crescimento e transformação-beta (TGF-B, transforming growth factorbeta), pode promover o desenvolvimento do tipo Th17, embora o TGF-6, em ambientes onde há inflamação, possa também conduzir para o perfil Th17 (BEDOYA ET AL, 2013).

Os linfócitos T regulatórios (Tregs) estão envolvidos na manutenção da tolerância periférica e no controle dos avanços das doenças inflamatórias crônicas. A presença das citocinas, IL-10 e TGF-B leva ao desenvolvimento dos linfócitos Tregs (VIGNALI ET AL, 2008). Há também uma população de linfócitos $\mathrm{T}$ conhecidos como linfócitos T de memória, os quais apresentam características morfofuncionais peculiares comparadas aos linfócitos $\mathrm{T}$ naive. São células capazes de responder rapidamente frente a um antígeno re-exposto, ou seja, há uma mudança na qualidade de resposta, que permite desenvolver respostas mais eficazes. Os linfócitos de memória apresentam uma maior expressão das moléculas de adesão, permitindo uma adesão mais intensa com as APCs (AHMED, GRAY, 1996).

Além dos linfócitos T, os linfócitos B participam da resposta alérgica. Sua principal função é síntese de anticorpos. Os linfócitos T que foram diferenciados em células efetoras migram para o folículo linfoide onde estão localizados os 
linfócitos B (OZDEMIR ET AL, 2010). O reconhecimento do alérgeno pelo linfócito B e a ligação das moléculas co-estimulatórias entre linfócitos B e T, leva à ativação dos linfócitos $\mathrm{B}$, que por sua vez, leva a mudança de classe do anticorpo IgM para IgE (HOLGATE, 2012).

\section{Imunoglobulinas e Alergia}

Imunoglobulinas (Igs) ou anticorpos (Acs) são proteínas solúveis produzidas pelos linfócitos B ativados, conhecidos como plasmócitos, em resposta aos antígenos. São proteínas que medeiam a resposta imune humoral, apresentam características estruturais comuns, e funcionalmente são específicas e diversificadas. O sistema imune adaptativo compreende cinco classes de imunoglobulinas: IgE, IgA, IgG, IgM e IgD (JUNIOR ET AL, 2010).

IgE é o anticorpo que possui uma função importante na defesa contra os parasitas. Está presente no sangue em baixas concentrações, possui um curto período de meia-vida devido à sua potente atividade. Está relacionada com a fisiopatologia das doenças alérgicas, assim como asma, alergia alimentar, anafilaxia e dermatite atópica. Em pacientes que apresentam essas doenças, o nível de $\operatorname{IgE}$ antígeno-específico é maior em comparação ao indivíduo saudável (WU, SCHEERENS, 2014). A IgE possui uma afinidade extremamente alta com o receptor FceRI, os quais são expressos em células como: mastócitos, basófilos, eosinófilos e células de Langerhans. Este anticorpo circulante regula positivamente a expressão do receptor FceRI dessas células. Desta forma, a forte ligação do anticorpo ao receptor gera uma regulação positiva e contribui para a potência desta IgE (SCHROEDER, CAVACINI, 2010).

A IgG é o anticorpo mais predominante e constitui $70 \%$ de todas as classes das Igs. É dividido em quatro subclasses de IgG referentes ao seu nível sérico presentes no sangue de um indivíduo saudável que encontramos desta forma: IgG1>IgG2>IgG3>IgG4. As subclasses apresentam distintas funções exercendo uma proteção imune sistêmica, como ligação a bactérias, vírus e fungos com alta afinidade (opsonização). Por exemplo, as IgG1 e IgG3 geralmente 
induzem uma resposta contra antígenos proteicos, entretanto, as IgG2 e IgG4 estão relacionadas a antígenos polissacarídicos (SCOTT-TAYLOR ET AL, 2017).

Há ainda uma diferença na afinidade entre os três tipos de receptores

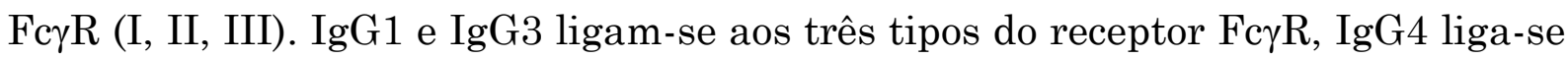
somente ao receptor Fc $\gamma R$ I e II, embora seja uma ligação mais fraca em relação a IgG1 e a IgG2 que liga-se apenas ao receptor FcrRII (SINGER, JAROLIM, 2014; SCHROEDER, CAVACINI, 2010)

$\mathrm{O}$ anticorpo mais abundante do tecido linfóide associado à mucosa é a IgA. A resposta deste anticorpo foi associada com o desenvolvimento da tolerância da mucosa (oral) e contribui como a primeira linha de defesa das regiões mucosas pela neutralização dos antígenos inalados e ingeridos.

A IgA possui baixa capacidade de ativação e inibição do complemento e ativação do macrófago, podendo ser representada como um isótipo não inflamatório, assim como, IgG4 (PILLETE ET AL., 2010). Há duas subclasses da IgA, as quais são: IgA1, predominante no soro na forma monomérica, e IgA2, presente nas secreções mucosas na forma dimérica, sendo chamada de IgA secretória (SIgA, secretory $\operatorname{Ig} \mathrm{A}$ ). A IgA monomérica liga-se com baixa afinidade ao receptor FcaRI e ativa o ITAM inibitório (ITAMi, motivo de ativação do imunorreceptor baseado em tirosina, sua ligação pode ativar ou inibir dependendo do ligante) o qual não conduz para a ativação celular ou degranulação/burst oxidativo, no caso dos granulócitos. Em contrapartida, o complexo IgA demonstra uma ativação mais forte e subsequente sinal de ativação, resultando na ativação celular (PASQUIER ET AL., 2004; GLOUDEMANS ET AL., 2013).

Foram descritos quatro receptores em que ocorre uma ligação com a IgA: FcaRI (CD89) expressos nas células mielóides como monócitos, neutrófilos, eosinófilos e células de Kupffer; receptor de Ig polimérica (pIgR, polimeric-Ig receptor) que transporta IgA e IgM polimérica através das células epiteliais da

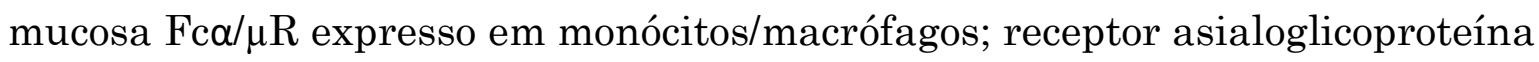


do hapatócito (ASGP-R); e receptor da transferrina (TfR ou CD71) (PASQUIER ET AL, 2004).

Estudos realizados in vitro demonstraram que a ligação cruzada do FcaRI com DCs derivados dos monócitos humanos conduz à internalização do complexo IgA e apresentação do antígeno, resultando na manutenção das DCs e produção de IL-10. A ligação da IgA sérica em monócitos induz a expressão de IL-10 e inibe citocinas inflamatórias como IL-6 e TNF (GLOUDEMANS ET AL., 2013)

Os anticorpos IgE e IgG específicos ao alérgeno da poeira domiciliar, por exemplo para Der p 1, estão envolvidos na alergia, porém cada um com interpretações diferentes. O IgE na fase inicial da alergia induz a degranulação dos mastócitos e contribui para o dano tecidual causado pela liberação dos grânulos provenientes dos mastócitos (HELLMAN ET AL, 2017). Estudos mostraram que este mesmo anticorpo poderia ser considerado um marcador da alergenicidade, uma vez que IgG específico ao alérgeno Der $p$ é quase exclusivamente produzido pelos pacientes alérgicos.

As imunoterapias utilizadas atualmente nas doenças alérgicas reduzem significativamente a inflamação alérgica, no entanto não apresentam melhora significativa na resposta, demonstrando a necessidade do desenvolvimento de novas modalidades terapêuticas. Assim, é importante investigar o tratamento que propicia o equilíbrio da resposta a linfócitos $\mathrm{T}$ que foram induzidos pelos alérgenos em pacientes atópicos.

A resposta inflamatória alérgica é caracterizada pela apresentação de antígenos pelas APCs para os linfócitos T naives, que direcionam a resposta para um perfil Th2. E em contraste, em indivíduos não alérgicos, há o predomínio de linfócitos Th1 e linfócitos $\mathrm{T}$ reguladores $\left(\mathrm{T}_{\text {regs }}\right)$. Nossa hipótese é que o tratamento com IgA e IgG in vitro é capaz de imunomodular a resposta das células dendríticas dos pacientes atópicos aos alérgenos Der p 1 e Der p 2. 


\section{O N C L U S Ã O}

(...) Nós não somos o que deveríamos ser.

Nós não somos o que queremos ser.

Nós não somos o que seremos.

Mas, graças a Deus, não somos o que éramos.

Martin Luther King Jr. 
Os dados obtidos no estudo nos permitem concluir que:

- Pacientes apresentam altas titulações de IgE, IgG e IgA específicas de ambos os alérgenos (Der p 1 e Der p 2) em relação ao controle;

- Há correlação entre IgE e IgG específicas para Der p 1 e Der p 2;

- Houve uma tendência à diminuição da liberação de IL-5 após tratamento com os imunocomplexos (Der p 1-IgG ou Der p 1-IgA), indicando uma possível utilização destes imunocomplexos no tratamento da alergia,

- O tratamento das DCs com os imunocomplexos Der p 1-IgG ou Der p 1-IgA, houve uma tendência a diminuição da expressão das moléculas de superfície CD40 e CD86, uma vez que estas, em condições de resposta alérgica, apresentaram níveis elevados. A molécula DC SIGN na presença de Der p 1 diminui a sua expressão.

A elevada titulação dos anticorpos específicos a Der p 1 e Der p 2 detectados nos pacientes e conjunto com os resultados obtidos dos ensaios in vitro, onde foram utilizados os imunocomplexos Der p 1-IgA ou Der p 1-IgG, sugerem que os anticorpos parecem atuar como uma função protetora, diminuindo a resposta Th2. Desta forma, os anticorpos IgG e IgA poderiam ser usados para atenuar a resposta alérgica, se associados a drogas, e possibilitariam a melhoria do tratamento de doenças atópicas. Uma vez que a fisiopatologia das doenças alérgicas é complexa e influenciada por vários fatores, são necessários mais estudos para a sua compreensão e esclarecimento. 


\section{R E F E R Ê N C I A S}

Ahmed R, Gray D. Immunological memory and protective immunity: understanding their relation. Science, v. 272, p. 54-60, 1996.

Ah-Ghouleh A, Johal R, Sharquie IR, Emara M, Harrington H, Shakib Farouk, Ghaemmaghami AM. The glicosylation pattern of common allergens: the recognition and uptake of Der $\mathrm{p} 1$ by epithelialand dendritic cells is carbohydrate dependent. Plos One, v. 7, n. 3, p. 1-11, 2012.

Akdis CA and Akdis M. Mechanisms of immune tolerance to allergens: role of IL10 and Tregs. The Journal of Clinical Investigation, v. 124, n. 11, p. 46784680, 2014.

Bacharier LB. Evaluation of the child with recurrent wheezing. Journal Allergy Clinical Immunology, v. 128, n. 3, p. 1-5, 2011.

Baldaçara RPC, Fernandes MFM, Baldaçara L, Aun WT, Mello JF, Pires MC. Prevalence of allergen sensitization, most important allergens and factors associated with atopy in children. Med J, v. 131, n. 5, p. 301-308, 2013.

Banchereau J, Steinman RM. Dendritic cell and the control of immunity. Nature, v. 392, p. 245-252, 1998.

Bedoya SK, Lam B, Lau K, Larkin III J. Th17 cells in immunity and autoimmunity. Clinical and Developmental Immunology, p. 1-16, 2013.

Berek C. Eosinophils: important players in humoral immunity. Clinical and Experimental Immunology, v. 183, p. 57-64, 2015.

Biagtan M, Viswanathan R, Bush RK. Immunotherapy for house dust mite sensitivity: where are the knowledge gaps? Curr Allergy Asthma Resp, v. 14, p. $482-488,2014$.

Calderon MA, Linneberg A, Tebbe JK, Blay FD, Rojas DHF, Virchow JC, Demoly P. Respiratory allergy caused by house dust mites: What do we really know? Journal Allergy Clinical Immunology, v. 136, p. 38-48, 2015;.

Celia M, Sallusto F, Lanzavecchia A. Origen, maturation and antigen presenting function of dendritic cells. Current Opinion in Immunology, v. 9, p. 10-16, 1997.

Conferência Científica Internacional da WAO (WISC 2014): 2014; Rio de Janeiro. Disponível em: <www.worldallergy.org/wisc2014 >: Acesso em: 03 Mar. 2017.

Criado RFJ, Wandalsen NF. Fatores ambientais em alergia. Alergia e imunologia na infância e na adolescência.2001:13-22. 
Delf S, Kitzmuller C, Steinberger P, Himly M, Jahn-Schmid B, Fischer GF, Zlabinger GJ, Bohle B. Differential activation of dendritic cells by toll-like receptors causes diverse differentiation of naive $\mathrm{CD} 4+\mathrm{T}$ cells from allergic patients. Allergy, v. 69, p. 1602-1609, 2014.

Deslée G, Charbonnier A-S, Hammad H, Angyalosi G, Leblond I-T, Mantovani A, Tonnel A-B, Pestel J. Involvement of the mannose receptor in the uptake of Der $p$ 1, a major mite allergen, by human dendritic cells. Basic and clinical immunology. J Allergy Clin Immunol, v. 110, p. 763-770, 2002.

Frischmeyer-Guerrerio PA, Keet CA, Guerrerio AL, Chichester KL, Bieneman AP, Hamilton RG, Wood RA, Schroeder JT. Modulation of dendritic cell innate and adaptative immune functions by oral and sublingual immunotherapy. Clinical Immunology, v. 155, p. 47-59, 2014.

Furmonaviciene R, Ghaemmaghami AM, Boyd SE, Jones NS, Bailey K, Willis AC, Sewell HF, Mitchell DA, Shakib F. The protease allergen Der p 1 cleaves cell surface DC-SIGN and DC-SIGNR: experimental analysis of in silico substrate identification and implications in allergic responses. Clinical and Experimental Allergy, v. 37, p. 231-42, 2007.

Ghaemmaghami AM, Gough L, Sewell HF, Shakib F. The proteolytic activity of the major dust mite allergen Der p 1 conditions dendritic cells to produce less interleukin-12: allergen-induced Th2 bias determined at the dendritic cell level. Clin Exp Allergy, v. 32, p. 1468-1475, 2002.

Galvão CES, Castro FFM. As alergias respiratórias. Revista de Medicina, São Paulo, v. 84, n. 1, p. 18-24, 2005.

Gershwin LJ. Comparative immunology of allergic responses. Annu Rev Anim Bioscience, v. 3, n. 17, p. 1-17, 2014.

Gloudemans AK, Lambrecht BN, Smits HH. Potential of Immunoglobulin A to Prevent Allergic Asthma. Clinical and Developmental Immunology, p. 1-12, 2013.

Gregory LG, Lloyd CM. Orchestrating house dust mite-associated allergy in the lung. Trends Immunology, v. 32, n. 9, p. 402-411, 2011.

Grumach AS. Alergia e imunologia na infância e na adolescência. São Paulo: Atheneu, 2001.

Hales BJ, Martin AC, Pearce LJ, Laing IA, Hayden CM, Goldblatt J, Soue"f PNL, Thomas WR. IgE and IgG anti-house dust mite specificities in allergic disease. Journal Allergy Clinical Immunololgy, v. 118, p. 361-367, 2006.

Hamilton RG. Diagnostic tests for human allergic disease. Expert opinion med diagn, v. 2, n. 10, p. 1123-1135, 2008. 
Hammad H, Smits HH, Ratajczak C, Nithiananthan A, Wierenga EA, Stewart GA, Jacquet A, Tonnel AB, Pestel J. Monocyte-derived dendritic cells exposed to Der $\mathrm{p} 1$ allergen enhance the recruitment of Th2 cells: major involvement of the chemokines TARC/CCL17 and MDC/CCL22. Eur Cytokine Network, v. 14, n. 4, p. 219-228, 2003.

Hawrylowicz CM, Garra AO. Potencial role of interleukin-10 - secreting regulatory T cells in allergy and asthma. Nature review. 2005;5:271-283. Holt PG, Thomas WR. Sensitization to airborne environmental allergens: inresolved issues. Nature Immunology, v. 6, n. 10, p. 957-960, 2005.

He SH, Zhang HY, Zeng XN, Chen D, Yang PC. Mast cells and basophils are essential for allergies: mechanisms of allergic inflammation and a proposed procedure for diagnosis. Acta Pharmacologica Sinica, v. 34, p. 1270-83, 2013.

Hellman LT, Akula S, Thorpe M, FU Z. Tracibg the origins of IgE, mast cells, and allergies by studies of wild animals. Frontiers in Immunology, v. 8, n. 1749, p. $1-22,2017$

Hilkens CMU, Kalinski P, Boer M, Kapsenberg ML. Human dendritic ceels exogenous interleukin-12 - Inducing factors to direct the development of naïve Thelper cells toward the th1 phenotype. Bood, v. 90, n. 5, p. 1920-1926, 1997.

Holgate ST. Innate and adaptive immune responses in asthma. Nature Medicine, v. 18, n. 5, p. 673-683, 2012.

Holgate ST, Polosa R. Treatment strategies for allergy and asthma. Nature reviews immunology, v. 8, p. 218-230, 2008.

Holt PG and Thomas WR. Sensitization to airborne environmental allergens: unresolved issues. Nature Immunology, v. 6, n. 10, p. 957-960, 2005.

Huber B. 100 years of allergy: Clemens von Pirquet - his idea of allergy and its immanent concept of disease, v. 118, n. (19-20), p. 573-579, 2006.

Jacquet A. The role of the house dust mite-induced innate immunity in development of allergic response. Int Arch Allergy Immunol. 2011; 555:95-105.

Junior MD, Araújo JAP, Catelan TTT, Souza AWS, Cruvinel WM, Andrade LEC, Silva NP. Sistema imunitário - parte II. Fundamentos da resposta imunológica mediada por linfócitos T e B. Revista Brasileira Reumatologia, v. 50, n. 5, p. 552-580, 2010.

Jutel M, Akdis CA. T-cell subset regulation in atopy. Curr. Allergy Asthma Rep, v. 11, p. 139-145, 2011.

Kalinski P, Hilkens CMU, Wierenga EA, Kapsenberg ML. T-cell priming by type1and type-2 polarized dendritic cells: the concept of a third signal. ViewPoint Immunology today, v. 20, n. 12, p. 561-567, 1999. 
Kay AB. Allergy and allergic diseases. N Engl J Med, v. 344, n. 1, p. 30-37, 2001.

Kim JH, Yoon MG, Seo DH, Kim BS, Ban GY, Ye YM, Shin YS, Park HS. Detection of Allergen Specific Antibodies From Nasal Secretion of Allergic Rhinitis Patients. Allergy Asthma Immunol Res, v. 8, n. 4, p. 329-337, 2016.

Lee JS, Kim IS, Ryu JS, Yun CY. House dust mite, Dermatophagoides pteronissinus increases expression of MCP-1, IL-6 and IL-8 in human monocytic THP-1 cells. Cytokine, v. 42, p. 365-371, 2008.

Lisa GG, Lloyd CM. Orchestrating house dust mite-associated allergy in the lung. Trends in Immunology, v. 32, n. 9, p. 402-411, 2011.

London JrR, Tharakan A, Ramanathan JrM. The role of innate immunity and aeroallergens in chronic rhinosinusites. Adv Otorhinolaryngol Basel, Karger, v. 79 , p. $66-77,2016$.

Minami T, Fukutomi Y, Lidholm J, Yasueda H, Saito A, Sekiya K, Tsuburai T, Maeda Y, Mori A, Taniguchi M, Hasegawa M, Akiyama K. IgE Abs to Der p 1 and Der p 2 as diagnostic markers of house dust mite allergy as defined by a bronchoprovocation test. Allergology International, v. 64, p. 90-95, 2015.

Morris FL, Luster AD. Allergen-Specific CD4+ T Cells in Human Asthma. State of the art, v. 13, n. 1, p. 25-30, 2016.

Ngoc LP, Gold DR, Tzianabos AO, Weiss ST, Celedón JC. Cytokines, allergy, and asthma. Curr Opin Allergy Clin immunol, v. 5, p. 161-166, 2005.

Nissen SP, Kjaer HF, Host A, Nielsen J, Halken S. The natural course of sensitization and allergic diseases from childhood to adulthood. Pediatr Allergy Immunol, v. 24, n. 6, p. 549-555, 2013.

Nunes C. A epidemiologia das doenças alérgicas. Revista Portuguesa de Imunoalergologia, v. 11, p. 169-199, 2003.

Ozdemir C, Akdis M, Akdis CA. T-cell response to allergens. Anaphilaxis Chem Immunol allergy, v. 95, p. 22-44, 2010.

Pasquier B, Lepelletier Y, Baude C, Hermine O, Monteiro RC. Differential expression and function of IgA receptors (CD89 and CD71) during maturation of dendritic cells. Journal of Leukocyte Biology, v. 76, p. 1134-1141, 2004.

Pilette C, Detry B, Guisset A, Gabriels J, Sibille Y. Induction of interleukin-10 expression through Fcalpha receptor in human monocytes and monocyte-derived dendritic cells: role of p38 MAPKinase. Immunology and Cell Biology, v. 88, p. 486-493, 2010. 
Raulf M, Bergmann KC, Kull S, Sander I, Hilger CH, Brüning T, Jappe U, Müsken H, Sperl A, Vrtala S, Zahradnik E, KlimekL. Mites and other indoor allergens - from exposure to sensitization and treatment. Allergo J Inter, v. 24, p. 68-80, 2015.

Rizzo MC. Asma: da infância à adolescência. Gaz méd, v. 78, n. 2, p. 93-102, 2008.

Roche N, Chinet TC, Huchon GJ. Allergic and nonallergic interactions between house dust mite allergens and airway mucosa. Eur Respir J, v. 10, p. 719-726, 1997.

Romagnani S. The increased prevalence of allergy and the hygiene hypothesis: missing immune deviation, reduced immune suppression, or both? Immunology, v. 112, p. 352-363, 2004.

Rönmark EP, Ekerljung L, Mincheva R, Sjölander S, Hagstad S, Wennergren G, Rönmark E, Lötvall J and Lundbäck B. Different risk factor patterns for adult asthma, rhinitis and eczema: results from West Sweden Asthma Study. Clinical and translational allergy, v. 6, n. 28, p. 1-10, 2016.

Rosales C. Fc $\gamma$ receptor heterogeneity in leukocyte functional responses.

Frontiers in immunology, v. 280, n. 8, p. 1-13, 2017.

Royer P-J, Emara M, Yang C, Al-Ghouleh A, Tighe P; Jones N; Sewell HF; Farouk Shakib; Martinez-Pomares L and Ghaemmaghami AM. The mannose receptor mediates the uptake of diverse native allergens by dendritic cells and determines allergen-induced $\mathrm{T}$ cell polarization through modulation of IDO activity. The journal of immunology, v. 185, p. 1522-1531, 2010.

Rutkowski K, Sowa P, Talipska JR, Sulkowski S,Rutkowski R. Allergic diseases: the price of civilisational progress. Derm Alergol, v. 2, p. 77-83, 2014.

Scott-Taylor TT, Stefan-Claudiu A, Sumeya A, Pettengell R. Immunoglobulin G; structure and functional implications of different subclass modifications in initiation and resolution of allergy. Immunitity, Inflammation and Disease, p. 1-21, 2017.

Schroeder HWJr, Cavacini L. Structure and Function of Immunoglobulins. J Allergy Clin Immunol, v. 125, n. 202, p. 41-52, 2010.

Serravalle K, Medeiros MJr. Ácaros da poeira domiciliar na cidade de SalvadorBA. Rev Bras Alerg Imunopatol, v. 22, p. 19-24, 1999.

Shakib F, Ghaemmaghami AM, Sewell HF. The molecular basis of allergenicity. Trends in immunology. Cell press, v. 29, n. 12, p. 633-642, 2008.

Sharquie IK, Ghouleh AA, Fitton P, Clark MR, Armour KL, Sewell HF, Shakib F, Ghaemmaghami. An investigation into IgE-facilitated allergen recognition and 
presentation by human dendritic cells. BMC Immunology, v. 14, n. 54, p. 1471$2172,2013$.

Singer J, Jarolim EJ. IgE-based Immunotherapy of Cancer -A Comparative Oncology Approach. J Carcinog Mutagen, v. 5, n. 3, p. 1-20, 2014.

Smart JM, Kemp AS. Increased Th1 and Th2 allergen-indudec cytokine responses in children with atopic disease. Clin Exp Allery, v. 32, p. 796-802, 2002.

Spieksma FTM, Dieges PH. The allergy archives. Journal Allergy Clin Immunol, p. 573-576, 2004.

Suzuki K, Fagarasan S. Diverse regulatory pathways for IgA synthesis in the gut. Mucosal Immunology Nature, v. 6, n. 2, p. 468-471, 2009.

Stiemsma T, Turvey ST. Asthma and the microbe: defining the critical window in early life. Allergy Asthma Clin Immunol, v. 13, n. 3, p. 1-9, 2017.

Tan H-TT, Sugita K, Akdis CA. Novel biologicals fot the treatment of allergic diseases and asthma. Curr Allergy Asthma Rep, v. 16, n. 70, p. 1-14, 2016.

Thomas WR, Hales BJ, Smith W-A. House dust mite allergens in asthma and allergy. Trends in Molecular Medicine, v. 16, p. 321-328, 2010.

Uphan JW. The role of dendritic cells in immune regulation and allergic airway inflammation. Respirology, v. 8, p. 140-148, 2003.

Vignali DAA, Collison LW, Workman CJ. How regulatory T cells work. Nat Rev Immunol, v. 8, n. 7, p. 523-5322008.

Wang J-Y. The innate immune response in house dust mite-induced allergic inflammation. Allergic asthma immunological research, v. 5, n. 2, p. 68-74, 2013.

Wu LC, Scheerens H. Targeting IgE production in mice and humans. Current Opinion in Immunology, v. 31, p. 8-15, 2014.

Yazdanbakhsh M; Kremsner PG; Ree van R. Allergy, parasites and the hygiene hypothesis. Science, v. 296, p. 490-494, 2002.

Yu S-J, Liao E-C, Tsai J-J. House dust mite allergy: environment evaluation and disease prevention. Asia pacific allergy, v. 4, p. 241-252, 2014. 